\title{
Immediate hypersensitivity to polyethylene glycols in unrelated products: when standardization in the nomenclature of the components of drugs, cosmetics, and food becomes necessary
}

\author{
Vicente Jover Cerdá ${ }^{*}$, Ramón Rodríguez Pacheco', Joan Doménech Witek',
} Francisco Manuel Marco de la Calle ${ }^{2}$ and María Luz de la Sen Fernández ${ }^{2}$

\begin{abstract}
Background: Polyethylene glycols (PEGs) and their derivatives are non-ionic polymers of ethylene oxide commercially available with numerous synonyms, such as macrogol, oxyethylene polymer, and laureth-9. Although these polymers are usually safe, mild to life-threatening immediate-type hypersensitivity reactions have been reported. Nevertheless, awareness about their allergic potential is minimal due to the non-standardization of their nomenclature.

Case presentation: We present the case of a 29-years-old woman who developed several local and systemic type I hypersensitivity reactions including a severe anaphylactic reaction to different pharmacologic and cosmetic products whose excipients included PEG. Prick tests and basophil activation tests were performed to several pharmacological and cosmetic products, but only those containing PEGs and their derivatives were positive. The patient was diagnosed with immediate hypersensitivity IgE-mediated to PEGs and its derivatives.

Conclusions: Standardization of the terminology used to describe the presence of PEGs in products would help patients to identify them clearly and unequivocally and thus avoid the development of hypersensitivity reactions. It is also recommended studying PEG allergy in reactions to products containing PEGs, once allergy to the active ingredients has been excluded and in reactions to multiple unrelated drugs.
\end{abstract}

Clinical study protocol number PI2018/29 (registered on 24 September 2018)

Keywords: Excipient allergy, Anaphylaxis, Basophil activation test, Hypersensitivity, Polyethylene glycol

\section{Background}

Polyethylene glycols (PEGs) and their derivatives are nonionic polymers of ethylene oxide commercially available over a wide range of molecular weights from $200 \mathrm{~g} / \mathrm{mol}$ to $35,000 \mathrm{~g} / \mathrm{mol}$ and widely used in medical, pharmaceutical, cosmetic, industrial, and food products $[1,2]$. These

\footnotetext{
*Correspondence: algena00@hotmail.com

1 Sección de Alergología, Hospital General Universitario de Elda, Ctra. De

Sax, s/n, 03600 Elda, Alicante, Spain

Full list of author information is available at the end of the article
}

polymers have numerous synonyms, such as macrogol, oxyethylene polymer, and laureth-9 [2]. Nevertheless, the term "PEG" is often used in combination with a number referring to the number of ethylene oxide units (cosmetic industry) or to the molecular weight (pharmaceutical industry) [2].

Since its development, PEG polymers held a reputation for safety, nevertheless from mild to life-threatening immediate-type hypersensitivity reactions have been reported, with clinical manifestations ranging from generalized urticaria to anaphylactic shock [2-5]. 
Awareness about the allergenic potential of these polymers is minimal due to the non-standardization of their nomenclature, inadequate labelling of products containing PEGs, and the lack of suspicion as the agents responsible of such reactions. In fact, no studies have examined the prevalence of type 1 PEGs hypersensitivity, so its incidence may have been underestimated.

\section{Case presentation}

We present the case of a 29-years-old woman with history of atopic eczema and contact dermatitis by nickel sulfate, subclinical sensitization to mites and cypress, and cholinergic urticaria. She developed several local and systemic type I hypersensitivity reactions including a severe anaphylactic reaction to different pharmacologic and cosmetic products whose excipients included PEGs.

Two years before consultation, the patient developed generalized urticaria, dizziness, and dyspnea $30 \mathrm{~min}$ after using a skin antiseptic (Betadine $^{\circledR}$ solution: iodopovidone and laureth-9 as excipient). Symptoms improved after treatment with dexchlorpheniramine and methylprednisolone. Six months later, $30 \mathrm{~min}$ after swallowing $30 \mathrm{ml}$ of a cough syrup (GripaNait ${ }^{\circledR}$ : paracetamol, dextromethorphan, and doxylamine as active ingredients and several excipients, including macrogol 6000), she developed generalized pruritus, dyspnea, severe dizziness, seizures, loss of consciousness, and respiratory arrest, requiring urgent treatment with adrenaline, plasma expanders, and parenteral corticosteroids. In the last 7 years she developed itchy maculopapular rashes in contact with some moisturizing skin creams containing PEG-75 and PEG-100. In May 2017, she reported generalized urticaria after applying soap to a tattooed area and wheals after applying a moisturizing creams on intact skin. In November 2017, she experienced swelling of the gums and tongue after using a toothpaste for which she did not need treatment.

An allergological study was carried out with her prior consent. Levels of C3, C4, IgA, IgG, IgM, and tryptase were all within normal range. Prick test and specific IgE were positive for mites and cypress, but negative for other aeroallergens, latex, anisakis, and several foods. Specific IgE was also negative for ethylene oxide. We detected $1626 \mathrm{IU} / \mathrm{ml}$ of total IgE.
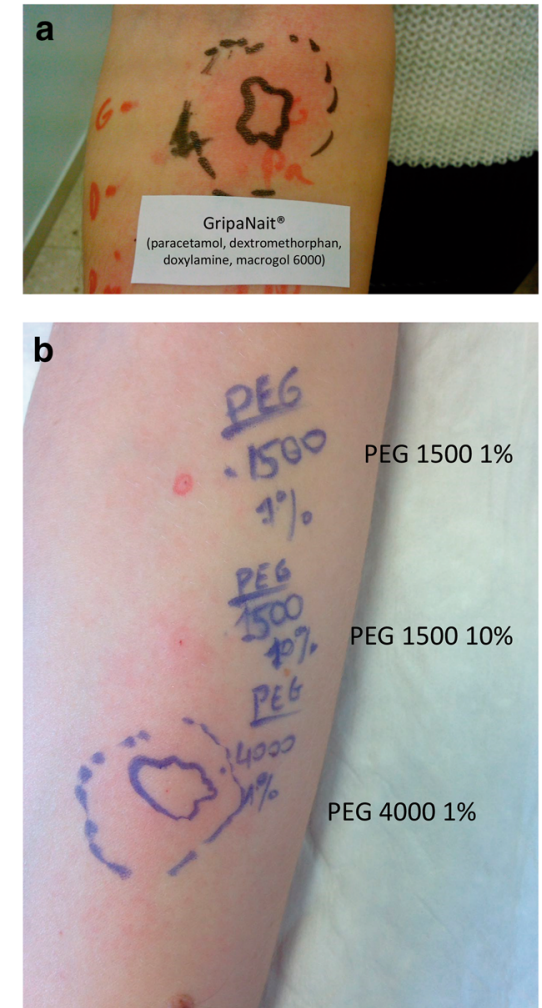
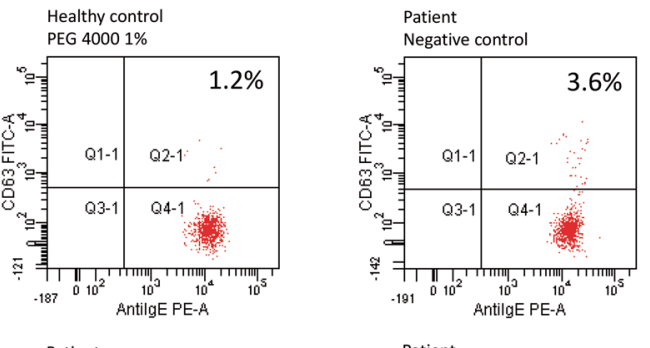

Dormidina $25 \mathrm{mg}$ tablets
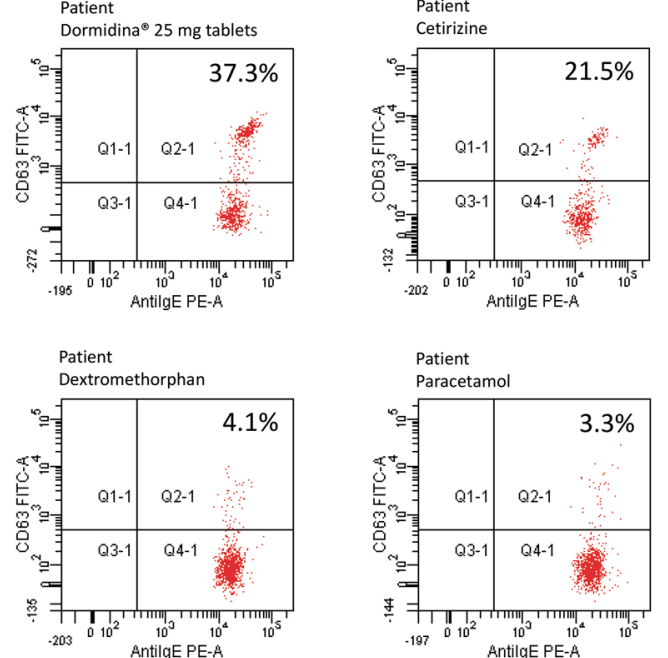

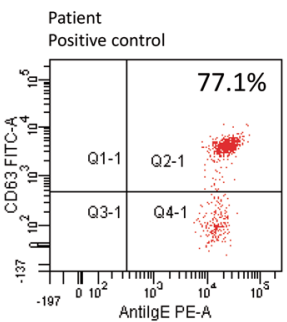

Patient

Ebaste ${ }^{\circledR}$ tablets
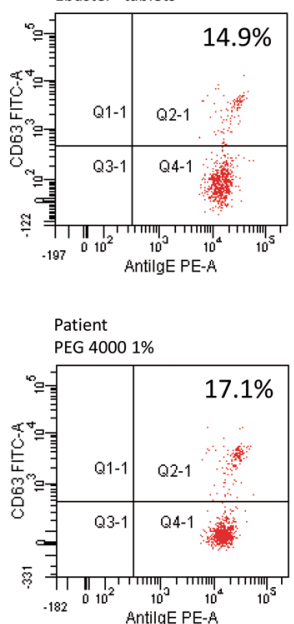

Fig. 1 Skin prick test and basophil activation test results. Skin prick test (left): a cough syrup GripaNait ${ }^{\circledR}$, containing paracetamol, dextromethorphan, doxylamine, and macrogol 6000; b PEG 1500 1\% and 10\% (negative), and PEG 4000 1\% (positive). Basophil activation test results (right): Q2-1 represents activated basophils CD63+lgE+ (\% indicated) and Q4-1 represents non-activated basophils CD63-IgE+. Positive control used anti-IgE antibody and negative control used isotonic solution 
Prick tests with GripaNait ${ }^{\circledR}$ (Fig. 1a) and Betadine ${ }^{\circledR}$ gel and solution were positive. Prick tests with each of their ingredients separately were negative, but positive for PEGs and doxylamine. To test doxylamine separately, we used Dormidina ${ }^{\circledR} 25 \mathrm{mg}$. Doxylamine is a histamine $\mathrm{H} 1$ receptor antagonist belonging to the ethanolamines group, such as diphenhydramine. To date few cases of allergy to these antihistamines have been described. One of such cases developed anaphylaxis to diphenhydramine included in the intranasal drops Coldistan ${ }^{\circledR}$ [6]. It is important to remark that Coldistan ${ }^{\circledR}$ contains PEG as excipient.

We noticed that the preparation of doxylamine used in our prick test (Dormidina ${ }^{\circledR} 25 \mathrm{mg}$ ) contained PEG 8000. For this reason, we retested doxylamine prick test with Cariban ${ }^{\circledR}$ tablets, a drug used as antiemetic that contains doxylamine plus pyridoxine, but without any PEG. Prick test with this drug resulted negative, as well as other antihistamines without PEG such as chlorpheniramine, diphenhydramine tablets, hydroxyzine, mepyramine, cetirizine solution, bilastine, and loratadine. Table 1 shows other products tested in our study. Of note, only products containing PEGs resulted positive in the prick tests. We also performed a basophil activation test (BAT) to the products listed in Table 1. Only products containing PEGs resulted positive, except the toothpaste containing PEG-6 that was negative, probably due to cytotoxic effects. All tests were compared with healthy volunteers resulting negative in all of them (Fig. 1). Negativity of BAT due to toxic effects was controlled by assaying a battery of decreasing concentrations of antigen. Non-specific activation was ruled out by testing healthy volunteers.

As all the products testing positive in the allergy work up contained PEGs (Table 1), its involvement as a causative agent in these reactions was confirmed with pure PEGs of different molecular weights and PEG-

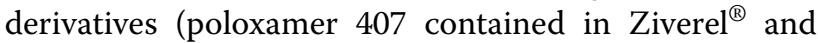
polysorbate 80 ) according to the algorithm proposed by Wenande et al. [2] for the investigation of patients with suspected immediate-type PEG hypersensitivity. PEG used was of analytical grade and purchased from Merck (Merck, Darmstadt, Germany). The test was negative with PEG $15001 \%$ and 10\%, but positive with PEG 4000 1\% (Fig. 1b). PEG-derivatives also resulted positive in the prick test. BAT resulted positive with PEG $40001 \%$ and PEG-derivatives (Fig. 1). Controls were done in healthy volunteers resulting negative in all of them. Taking into account that there are studies that have reported delayed hypersensitivity reactions to PEGs [7], a patch test was performed with Betadine ${ }^{\circledR}$ solution, GripaNait ${ }^{\circledR}$, Ziverel $^{\circledR}$, polysorbate 80, and PEG $400010 \%$, but it was negative in all products.

The patient was diagnosed with immediate hypersensitivity IgE-mediated to PEG and its derivatives of different molecular weights contained in pharmacological and cosmetic products, with severe anaphylaxis to cough syrup (containing PEG 6000), moderate anaphylaxis to a skin antiseptic (containing PEG-9), contact urticaria or generalized urticaria to moisturizing skin creams (PEG-75 and PEG-100, respectively), contact angioedema by toothpaste (PEG6), and subclinical skin and in vitro (BAT) sensitivity to poloxamer 407 and polysorbate 80 . Interestingly, she does not currently show problems with foods that may contain such products. After recommending avoidance measures to such products by providing her with a list of PEG-free products and their derivatives, she has not experienced any further allergic reactions in the last year. It was recommended to carry on an emergency kit including an auto-injectable adrenaline shot.

\section{Discussion and conclusion}

Although this type of hypersensitivity reactions have been previously described in 37 patients included in the study of Wanande et al. [2] only 4 were assessed through the BAT. In our case we demonstrated an immediate hypersensitivity IgE-mediated to PEG by positive skin prick test and positive BAT. We ruled out delayed hypersensitivity with a negative patch test.

As in 2 of 37 patients of Wanande trial, we didn't find specific IgE against ethylene oxide [2]. However, our results give limited information on the safety of ethylene oxide for patients sensitized to PEG. IgE test was negative, but we cannot rule out a potential reaction in vivo. Nevertheless, the lesser reactivity observed when assaying PEGs of decreasing molecular weight, may indicate that monomeric ethylene oxide could be devoid of allergenicity by itself, unless conjugated to a complex carrier molecule (i.e. a hapten-carrier mechanism).

The lack of standardization in the nomenclature of PEGs and lack of knowledge about the involvement of PEGs in hypersensitivity reactions means that many patients are not properly diagnosed and develop adverse reactions to many unrelated products. We recommend standardizing the terminology used to describe the 
Table 1 Products assessed by skin prick test and basophil activation test

\begin{tabular}{|c|c|c|c|}
\hline Drugs (active ingredients) & Contains PEG & Prick test & BAT \\
\hline $\begin{array}{l}\text { GripaNait }^{\circledR} \text { cough syrup } \\
\text { (paracetamol, dextromethorphan, doxylamine) }\end{array}$ & $\stackrel{+}{\text { (macrogol 6000) }}$ & + & NP \\
\hline $\begin{array}{l}\text { Betadine }{ }^{\circledR} \text { solution } \\
\text { (iodopovidone) }\end{array}$ & $\stackrel{+}{\text { (laureth-9) }}$ & + & NP \\
\hline $\begin{array}{l}\text { Betadine }{ }^{\circledR} \text { gel } \\
\text { (iodopovidone) }\end{array}$ & $\stackrel{+}{(\text { PEG 400, } 4000 \text { and } 6000)}$ & + & NP \\
\hline $\begin{array}{l}\text { Romilar }^{\circledR} \text { tablets } \\
\text { (dextromethorphan) }\end{array}$ & - & - & - \\
\hline $\begin{array}{l}\text { Dormidina }{ }^{\circledR} 25 \text { mg tablets } \\
\text { (doxylamine) }\end{array}$ & $\stackrel{+}{(\text { PEG 8000) }}$ & + & + \\
\hline $\begin{array}{l}\text { Dormidina }{ }^{\circledR} 12.5 \mathrm{mg} \\
\text { tablets (doxylamine) }\end{array}$ & $\begin{array}{l}+ \\
(\mathrm{PEG} 400 \text { and } 6000)\end{array}$ & Weak + & NP \\
\hline $\begin{array}{l}\text { Cariban }{ }^{\circledR} \text { tablets } \\
\text { (doxylamine, pyridoxine) }\end{array}$ & - & - & NP \\
\hline $\begin{array}{l}\text { Polaramine }{ }^{\circledR} \text { solution } \\
\text { (dexchlorpheniramine) }\end{array}$ & - & - & - \\
\hline $\begin{array}{l}\text { Soñodor }{ }^{\circledR} \text { tablets } \\
\text { (diphenhydramine) }\end{array}$ & - & - & - \\
\hline $\begin{array}{l}\text { Atarax }{ }^{\circledR} \text { solution } \\
\text { (hydroxyzine) }\end{array}$ & - & - & NP \\
\hline $\begin{array}{l}\text { FLUIDASA }^{\circledR} \text { solution } \\
\text { (mepyramine) }\end{array}$ & - & - & - \\
\hline $\begin{array}{l}\text { Cetirizine solution } \\
\text { (cetirizine) }\end{array}$ & - & - & NP \\
\hline $\begin{array}{l}\text { CETIRIZINE tablets } \\
\text { (cetirizine) }\end{array}$ & $\stackrel{+}{\text { (macrogol 4000) }}$ & + & + \\
\hline $\begin{array}{l}\text { Ebastel }^{\circledR} \text { tablets } \\
\text { (ebastine) }\end{array}$ & $\stackrel{+}{(\text { macrogol 6000) }}$ & + & + \\
\hline $\begin{array}{l}\text { Ebaste }^{\circledR} \text { solution } \\
\text { (ebastine) }\end{array}$ & $\begin{array}{l}+ \\
\text { (oxyethylene polymer) }\end{array}$ & + & + \\
\hline $\begin{array}{l}\text { Bilaxten }{ }^{\circledR} \text { tablets } \\
\text { (bilastine) }\end{array}$ & - & - & - \\
\hline $\begin{array}{l}\text { Loratadine tablets } \\
\text { (loratadine) }\end{array}$ & - & - & NP \\
\hline $\begin{array}{l}\text { Movicol }^{\circledR} \text { powder } \\
\text { (macrogol 3350, sodium chloride, sodium bicarbonate, potassium } \\
\text { chloride) }\end{array}$ & $\begin{array}{l}+ \\
\text { (macrogol 3350) }\end{array}$ & + & + \\
\hline $\begin{array}{l}\text { PEG } 1500 \\
(1 \% \text { and } 10 \%)\end{array}$ & $\stackrel{+}{(\text { PEG 1500) }}$ & - & NP \\
\hline $\begin{array}{l}\text { PEG } 4000 \\
(1 \%)\end{array}$ & $\begin{array}{l}+ \\
(\text { PEG 4000) }\end{array}$ & + & + \\
\hline ORAL-B ${ }^{\circledR}$ toothpaste & $\stackrel{+}{+}$ & - & - \\
\hline $\begin{array}{l}\text { Zivere }^{\circledR} \text { powder } \\
\text { (hyaluronic acid, chondroitin sulfate) }\end{array}$ & $\begin{array}{l}+ \\
\text { (poloxamer 407) }\end{array}$ & + & + \\
\hline $\begin{array}{l}\text { Polysorbate } 80 \\
(1 \% \text { and } 20 \%)\end{array}$ & $\begin{array}{l}+ \\
\text { (polysorbate 80) }\end{array}$ & $\begin{array}{l}- \text { in } 1 \% \\
+ \text { in } 20 \%\end{array}$ & $\begin{array}{l}\text { - at } \\
0.002 \mathrm{mg} / \\
\mathrm{ml} \\
+\mathrm{at} \\
0.02 \mathrm{mg} / \\
\mathrm{ml}\end{array}$ \\
\hline $\begin{array}{l}\text { Citrafleet }^{\circledR} \text { powder } \\
\text { (sodium picosulfate, magnesium oxide, citric acid) }\end{array}$ & - & - & - \\
\hline Paracetamol tablets & - & - & - \\
\hline
\end{tabular}


presence of PEG in products to avoid confusions and studying PEG allergy in reactions to products containing PEG, once allergy to the active ingredients has been excluded and in reactions to multiple unrelated drugs.

\section{Abbreviations}

BAT: basophil activation test; PEG: polyethylene glycol.

\section{Authors' contributions}

VJC was responsible for the patient and who established the diagnosis; carried out the allergological study, and prick tests; and drafted the manuscript. RRP carried out the allergological study, and prick tests; and build the table containing products assessed by skin prick test and basophil activation test. JDW carried out the allergological study, and prick tests. FMMC and MLSF carried out the development, performance, and interpretation of the basophil activation test to PEGs and products containing PEGs. All the authors analyzed and discuss the results. All authors read and approved the final manuscript.

\section{Author details}

${ }^{1}$ Sección de Alergología, Hospital General Universitario de Elda, Ctra. De Sax s/n, 03600 Elda, Alicante, Spain. ${ }^{2}$ Servicio de Análisis Clínicos e Inmunología, Hospital General Universitario de Alicante, Alicante, Spain.

\section{Acknowledgements}

The authors wish to thank Dr. Fernando Sánchez Barbero for his help in the preparation of the manuscript.

\section{Competing interests}

VJC in the last years has received honoraria for speaking at sponsored meetings from Astrazeneca; help assistance for participating in research work by Merck; and received help assistance to working-meetings organized by Belloch, and GlaxoSmithKline and conferences by Menarini, and Allergy Therapeutics.

RRP in the last years has received honoraria for speaking at sponsored meeting from Astrazeneca, and Allergy Therapeutics; help assistance for participating in research work by Merck; and received help assistance to working-meetings organized by Belloch, Novartis, Leti, Uriach, and Steve and conferences by Leti, Immunotech, Chiesi, Uriach, Steve, and MSD.

JDW in the last years has received help assistance for participating in research work by Merck, and Belloch; and help assistance to workingmeetings organized by GlaxoSmithKline, and Merck and conferences by Allergy Therapeutics.

FMMC in the last years has received help assistance to assist to workshop organized by One Lambda, and Shire.

MLSF in the last years has received help assistance to assist to workshop organized by One Lambda, and Shire.

\section{Availability of data and materials}

Data sharing not applicable to this article as no data-sets were generated or analyzed during the current study.

\section{Consent for publication}

Written informed consent was obtained from the patient for publication of this case report, including the accompanying images. A copy of the written consent is available for review by the Editor-in-Chief of this journal. The patients gave their consent for the publication of the results both at the beginning and at the time of submission to the journal.

\section{Ethics approval and consent to participate}

Having successfully completed all the requirements imposed by the authorities of Spain, including those of the Declaration of Helsinki and Norms of Good Clinical Practice of the European Union, this case report was approved by the Institutional Review Board of Elda General University Hospital (Elda, Spain), with the Clinical Study Protocol, Number PI2018/29.

\section{Funding}

Roxal provided financial support for medical writing services. This case report did not receive any other specific grant from funding agencies in the public, commercial, or not-for-profit sectors.

\section{Publisher's Note}

Springer Nature remains neutral with regard to jurisdictional claims in published maps and institutional affiliations.

Received: 9 November 2018 Accepted: 9 February 2019

Published online: 19 February 2019

\section{References}

1. French AC, Thompson AL, Davis BG. High-purity discrete PEGoligomer crystals allow structural insight. Angew Chem Int Ed Engl. 2009;48(7):1248-52

2. Wenande $\mathrm{E}$, Garvey LH. Immediate-type hypersensitivity to polyethylene glycols: a review. Clin Exp Allergy. 2016;46(7):907-22.

3. Fruijtier-Polloth C. Safety assessment on polyethylene glycols (PEGs) and their derivatives as used in cosmetic products. Toxicology. 2005;214(1-2):1-38.

4. Badiu I, Guida G, Heffler E, Rolla G. Multiple drug allergy due to hypersensitivity to polyethylene glycols of various molecular weights. J Investig Allergol Clin Immunol. 2015;25(5):368-9.

5. Oyarzabal NA, Areso NL, Belar NB, Popolizio IG, Arregui AV, de Vallejo OVB. Anaphylactic shock due to allergy to macrogol 4000 contained in SonoVue ${ }^{\circledR}$. Case Rep Clin Med. 2017;6(6):143-7.

6. Au EYL, Rosa Duque JS, Lau CS, Chan E. A patient with anaphylaxis to diphenhydramine without cross-reactivity to loratadine. J Allergy Clin Immunol Pract. 2018;6(3):1061-3.

7. Ozkaya E, Kilic S. Polyethylene glycol as marker for nitrofurazone allergy: 20 years of experience from Turkey. Contact Dermat. 2018;78(3):211-5.

Ready to submit your research? Choose BMC and benefit from:

- fast, convenient online submission

- thorough peer review by experienced researchers in your field

- rapid publication on acceptance

- support for research data, including large and complex data types

- gold Open Access which fosters wider collaboration and increased citations

- maximum visibility for your research: over $100 \mathrm{M}$ website views per year

At BMC, research is always in progress.

Learn more biomedcentral.com/submissions 